\title{
Accuracy Analysis of Gagan for Different Types of Surveying Applications
}

\author{
Dilshan K.A.D.* ${ }^{*}$ Prabath W.M.H.C., Tharanga P.V.D. and Dammalage T.L. \\ Department of Remote Sensing and GIS, Faculty of Geomatics \\ Sabaragamuwa University of Sri Lanka
}

\begin{abstract}
With the advancements of technology, the use of GNSS technology in all the surveying applications are significantly growing due to its many several advantages over conventional techniques. However, in most of all surveying applications, the preservation of reliability and positional accuracy should be according to the national surveying standards published by Survey Department of Sri Lanka. Therefore, the uses of GPS augmentation systems with local and wide area differential positioning capabilities have increased demand. Considering the facts, two networks of Continuously Operating Reference Stations (CORS) were established in Sri Lanka, covering a part of Colombo district for real-time augmentation as a paid local area service. While it provides higher accurate differential service the users should have mobile internet with additional hardware, limited coverage and has a cost for the service as well. Satellite-Based Augmentation Systems (SBAS) are being developed worldwide due to their unique advantage of wide area coverage. Similarly, along with Airports Authority of India (AAI), Indian Space Research Organization (ISRO) has worked out a joint project to implement the Satellite Based Augmentation System using GPS, called GAGAN (GPS Aided Geo Augmented Navigation). With the free use and availability of GAGAN in Sri Lanka, this study focuses on validating the applicability of GAGAN in various surveying methods in Sri Lanka. In order to test its performances, Control Surveying, Boundary Surveying and Road Surveying have done with a GAGAN active GNSS receiver by comparing with uncorrected standard positioning. Further, 24 hours of static observations were also collected with GAGAN active GNSS receiver to check the reliability of its use at any time of the day. It is found that accuracy in those applications has improved significantly in SBAS receiver due to real-time GAGAN corrections except in urban and forest areas (disturbing conditions). Further, 24-hour observations confirmed that GAGAN is capable of giving 92.6\% of below 1-meter 2D positional accuracy at any time of the day.
\end{abstract}

KEYWORDS: GNSS, GAGAN, Field Surveying, Accuracy

Corresponding author: Dilshan K. A. D., Email: dilshan.ka@hotmail.com 


\section{INTRODUCTION}

SBAS is a free to air regional augmentation service where corrections are derived from a regional network of reference stations and transmitted to users via geostationary satellites. DGPS uses the ground reference station to determine the difference between the positions indicated by the navigation satellites. As SBAS gives free wide area coverage, it is a very useful utility than other correction methods.

There are several errors that affect GPS co-ordinations such as Satellite errors, Ionosphere errors, Troposphere errors, and multipath errors etc. Professional surveying works need more accurate, reliable, continuously available and costeffective correction services. So DGPS and SBAS can be used for more precise services. But SBAS possesses several advantages than DGPS, such as costeffectiveness, wide area coverage and time effectiveness. India has its own SBAS (GAGAN) and it covers Sri Lankan region as well. But its applicability on surveying applications is not yet validated according to the different types of surveying methods in Sri Lanka. Therefore in this research, the accuracy analysis of GAGAN was done for the different type of surveying applications. The objectives of this study are, (1) To check the applicability and 2D accuracy of GAGAN for Boundary Survey, Road Survey and Control point establishment in Sri Lanka, (2)To check the availability and the 2D accuracy of GAGAN in different environmental conditions in day and night observations (Balangoda region). According to the objectives, it is evident that the system has checked the Suitability of GAGAN for Boundary Survey, Road Survey, Control Survey and the accuracy of GAGAN observations in both day and night.

\section{METHODOLOGY}

Precise Point Positioning (PPP) method was used to assign co-ordinations to the station NSG01. (This point was used as the base station of all control point establishments)

Initial surveys were done and the control points were established where necessary to conduct the Total Station traverses. Then, Total Station traverses were run to capture the data of Open, Urban and Forest boundaries and also to capture the center lines of Roads on selected Open, Urban and Forest areas.

Table 1: Selected Locations

\begin{tabular}{|l|c|c|c|}
\hline & Open Area & Urban Area & Forest Area \\
\hline Boundary Survey & $\begin{array}{c}\text { Main Playground of } \\
\text { SUSL }\end{array}$ & Balangoda Town & $\begin{array}{c}\text { Near the Faculty of } \\
\text { Applied Sciences }\end{array}$ \\
\hline Road survey & Balangoda & Balangoda Town & Nonperial Road \\
\hline $\begin{array}{l}\text { Control Point } \\
\text { Establishment }\end{array}$ & NSG01 & Faculty premises & Nonperial \\
\hline
\end{tabular}

The same points were observed by GNSS receiver using GAGAN activated GPS receiver, Uncorrected GPS. The time periods were selected as four sets of three- 
hour observations, ( 1 pm to $4 \mathrm{pm}, 5 \mathrm{pm}$ to $8 \mathrm{pm}, 11 \mathrm{pm}$ to 2 am and 4 am to $7 \mathrm{am}$ ) to cover up 24 hours to check the accuracy of GAGAN over the time.

\section{RESULTS}

\section{Boundary Surveying}

Table 2: Percentages of overall 2D positional accuracy of GAGAN for Boundary survey

\begin{tabular}{|c|c|c|c|c|c|}
\hline Accuracy Level & $\leq 0.3 \mathrm{~m}$ & $\leq 0.5 \mathrm{~m}$ & $\leq 1 \mathrm{~m}$ & $\leq 2 \mathrm{~m}$ & $\leq 5 \mathrm{~m}$ \\
\hline Open Area \% & 18 & 84 & 100 & 100 & 100 \\
\hline Urban Area \% & 0 & 5 & 16 & 47 & 63 \\
\hline Forest Area \% & 0 & 6 & 18 & 65 & 0 \\
\hline
\end{tabular}

The average linear distortion of boundary surveying in open area with GAGAN is $0.4 \mathrm{~m}$.In urban areas, there is an average linear distortion of $5.21 \mathrm{~m}$ and the forest area depicts an average of $1.46 \mathrm{~m}$. The huge deviation in the urban area may cause by the existence of electric transmissions and huge buildings

\section{Overall area accuracy of GAGAN}

\section{Table 3:}

\begin{tabular}{|c|c|c|c|}
\hline & Open Area & Urban Area & Forest Area \\
\hline $\begin{array}{c}\text { Area Difference }\left(\mathrm{m}^{2}\right) \\
\text { (TS - GAGAN) }\end{array}$ & 62.482 & 488.77 & 86.45 \\
\hline $\begin{array}{c}\text { Acceptable area difference } \\
\text { for cadastral surveying }\left(\mathrm{m}^{2}\right)\end{array}$ & 10.863 & 10.772 & 10.02 \\
\hline
\end{tabular}

For cadastral surveying, the acceptable area difference is calculated according to the regulations of the Survey Department in Sri Lanka. It is based on the following equation.
$\Delta €=+-0.04[\mathrm{P} \sin (360 / \mathrm{N})] 1 / 2$

$\{\Delta €$ - Acceptable difference in Perches, $\mathrm{P}$ Area computed in perches, $\mathrm{N}$ - Number of Observed points

\section{Road Surveying}

Table 4: Percentages of overall 2D positional accuracy of GAGAN for Road

\begin{tabular}{|c|c|c|c|c|c|}
\hline Accuracy Level & $\leq 0.3 \mathrm{~m}$ & $\leq 0.5 \mathrm{~m}$ & $\leq 1 \mathrm{~m}$ & $\leq 2 \mathrm{~m}$ & $\leq 5 \mathrm{~m}$ \\
\hline Open Area \% & 31 & 83 & 97 & 100 & 100 \\
\hline Urban Area \% & 0 & 4 & 20 & 32 & 52 \\
\hline Forest Area \% & 17 & 29 & 43 & 63 & 91 \\
\hline
\end{tabular}

Road surveying (linear feature) from GAGAN in open area has an average accuracy of $0.40 \mathrm{~m}$. The average accuracy in the urban area is $5.3 \mathrm{~m}$ while Road surveying in forest area gives an average accuracy of $1.85 \mathrm{~m}$. 
Table 5: Overall length accuracy of GAGAN for Road

\begin{tabular}{|l|c|c|c|}
\hline & Open Area & Urban Area & Forest Area \\
\hline $\begin{array}{l}\text { Length Difference (m) } \\
\text { (GAGAN - TS) }\end{array}$ & -0.72 & 25.23 & 10.63 \\
\hline
\end{tabular}

\section{Control point establishment}

In control point establishing, $1 \mathrm{~m}$ accuracy can be achieved by GAGAN signal, yet in forest area, it was unsuccessful due to the canopy around the point.

Table 6: Accuracy assessment for Control Point Establishment in Open Area

\begin{tabular}{|l|c|c|}
\hline & E (m) & N (m) \\
\hline NSG01 (PPP) & 501892.359 & 467958.795 \\
\hline NSG01 (GAGAN) & 501891.514 & 467958.498 \\
\hline Difference (PPP-GAGAN) & 0.845 & 0.297 \\
\hline Linear Distortion (m) & \multicolumn{2}{|c|}{0.896} \\
\hline
\end{tabular}

Table 7: Accuracy assessment for Control Point Establishment in Urban Area

\begin{tabular}{|l|c|c|}
\hline & E $(\mathrm{m})$ & $\mathrm{N}(\mathrm{m})$ \\
\hline FOG01 (DGPS) & 501810.285 & 467793.582 \\
\hline FOG01 (GAGAN) & 501809.566 & 467793.258 \\
\hline Difference (DGPS-GAGAN) & 0.719 & 0.324 \\
\hline Linear Distortion (m) & \multicolumn{2}{|c|}{0.788} \\
\hline
\end{tabular}

\section{Hours Observation (Open area)}

Table 8: Percentages of 2D positional accuracy at NSG01- 24h covering observation

\begin{tabular}{|l|c|c|c|}
\hline Distortion & $\leq 0.5 \mathrm{~m}$ & $\leq 1 \mathrm{~m}$ & $>1 \mathrm{~m}$ \\
\hline $1 \mathrm{PM}-4 \mathrm{PM}$ & $13 \%$ & $81 \%$ & $19 \%$ \\
\hline $5 \mathrm{PM}-8 \mathrm{PM}$ & $33 \%$ & $100 \%$ & $0 \%$ \\
\hline $11.30 \mathrm{PM}-2.30 \mathrm{AM}$ & $23 \%$ & $85 \%$ & $15 \%$ \\
\hline $4 \mathrm{AM}-7 \mathrm{AM}$ & $52 \%$ & $100 \%$ & $0 \%$ \\
\hline Overall & $30 \%$ & $93 \%$ & $7 \%$ \\
\hline
\end{tabular}




\section{CONCLUSION(S)}

GAGAN is suitable for general mapping and GIS applications for boundary surveying in an open area and also suitable for mapping road features in small scale maps.

Open - 1:1000 and smaller

Urban - 1:25,000 and smaller

Forest $-1: 10,000$ and smaller

The accuracy of GAGAN is not enough for cadastral surveying.

\section{REFERENCES}

Dammalage, T., De Silva, D. N., \&Satirapod, C. (2017). Performance Analysis of GPS Aided Geo Augmented Navigation (GAGAN) Over Sri Lanka. Engineering Journal (Eng. J.)

Murugan, B. (2014). The land-based positional accuracy of GPS and GPS augmented by GAGAN over the Indian geographical region. International Journal of Scientific \& Technology Research, 3(4)

Suryanarayana Rao, K.N. (2007) GAGAN-The Indian Satellite Based Augmentation System. Indian Journal of Radio \& Space Physics, 36, 293-302.

Federal Aviation Administration [FAA] (1997), Wide Area Augmentation System (WAAS) Specifications. Department of Transportation, FAA-E-2892B, March 10,1997

Ashkenazi, V., C.J. Hill, W.Y. Ochieng and J. Nagle (1993), Wide Areas Differential GPS: A Performance Study. NAVIGATION: Journal of The Institute of Navigation, vol. 40, no. 3, Fall 1993, pp. 